\title{
O APRISIONAMENTO DAS MENTES E DOS CORAÇÕES DOS ESTUDANTES BRASILEIROS PELO SISTEMA DE AVALIAÇÃO*
}

\author{
João Batista Zanardini
}

\section{Introdução}

O presente capítulo versa sobre o impacto que a avaliação em larga escala possui nas escolas e, principalmente, na vida dos estudantes brasileiros. Dessa forma, abordou-se, inicialmente, sobre vários aspectos atinentes à implementação dessas avaliações, bem como a sua principal intencionalidade: incorporar vigorosamente à educação pública uma lógica empresarial contemporânea em que os resultados e a competição se sobrepõem aos elementos essenciais dos processos de aprendizagem. Realizou-se uma inter-relação entre as intenções da Base Nacional Comum Curricular e o controle do ensino por meio das avaliações externas em larga escala com foco nas competências socioemocionais ou não cognitivas

Muito embora as avaliações em larga escala não se constituam em um fenômeno típico dos anos noventa ou do início do século vinte e um, é justamente nesse período que as mesmas recrudescem no âmbito das políticas educacionais nacionais. Ao considerarmos a publicização dos resultados obtidos por alunos das escolas brasileiras em testes avaliativos em larga escala, quer sejam nacionais ou internacionais, como o SAEB, PROVA BRASIL e PISA, constatamos que os problemas educacionais, tomados como reflexo do baixo rendimento dos alunos nesses testes, servem, muitas vezes, de justificativa para problemas sociais mais amplos, como, por exemplo, a pobreza, o desemprego e outras condições de miserabilidade.

Vejamos que entre 2014 e 2017, o número de pessoas vivendo abaixo daquilo que se considera como a linha da pobreza no Brasil cresceu $33 \%$, o que equivale a um aumento de 6,3 milhões de novos pobres no país ${ }^{1}$. Esses números foram apontados em pesquisa realizada pela Fundação Getúlio Vargas - FGV. Nessa perspectiva, explicando qual grupo seria um dos mais vulneráveis, Neri afirma que:

Todos perderam, mas os pobres perderam mais. Os principais perdedores são os jovens, as pessoas com pouca educação, os chefes de família, as pessoas do Norte e Nordeste. Esses perderam mais que a média", completa. Segundo o estudo, os estratos que tiveram as maiores perdas na renda foram jovens de 15 a 19 anos ($20 \%)$; pessoas com até oito anos de estudo $(-11,6 \%)$ e os moradores do Nordeste $(-6,4 \%)$. (2018, s/p.)

Logo, defendemos que há uma aposta subjacente à intencionalidade de tornar visível o aparente anacronismo da escola na veiculação, por mais paradoxal que

"DOI - 10.29388/978-65-86678-87-1-0.f.83-99

${ }^{1}$ Equivalente a quase duas vezes a população do Uruguai, que é de aproximadamente 3,5 milhões de pessoas. 
pareça, de um modelo de educação que se propaga como a ideal, aquela que se mostra como uma imprescindível forma de ajuste das desigualdades sociais. A educação eficiente, capaz de reverter os baixos escores dos estudantes nos testes avaliativos, assim, dotá-los-ia de habilidades e competências que funcionariam como chave para a saída de sua condição econômica desfavorável. A solução apontada não retiraria esses sujeitos de sua condição material, porém, atuaria por meio de um empoderamento subjetivo, tornando-os, assim, pobres eficientes e sob controle.

Neste sentido, discute-se muito acerca de políticas estruturadoras que minorem os problemas associados à pobreza, bem como em instrumentos de políticas para que não se perpetuem os programas de cunho assistencialistas, sempre muito úteis no aprisionamento político do cidadão. A esse respeito, existe consenso em toda a sociedade acerca da importância do papel que a educação desempenharia no processo de redução permanente da pobreza. Além de eficaz contra a pobreza, as vantagens de uma sociedade mais educada parecem incontestes (Lange y Topel, 2006). A educação traz inúmeros benefícios sociais: um indivíduo melhor educado tem maior produtividade, maior noção de cidadania, além de possuir maior portfólio para decidir sobre nutrição, saúde e planejamento familiar (Gurgand, 2005).Vários estudos têm apontado para a importância da melhoria da qualidade da educação brasileira e a elevação de seus níveis, como etapa para resolução dos diversos problemas socioeconômicos que o Brasil enfrenta, inclusive, no que tange à atenuação da pobreza (Ferreira y Veloso, 2006 y Barros, Mendonça y Henriques, 2001). Entretanto, o sistema educacional brasileiro parece se encontrar imergido no seio desses mesmos problemas. Assim, a educação deixa de ser uma panacéia para ser objeto de estudos. (SILVA JÚNIOR E SAMPAIO, p. 76, 2010)

Dessa forma, uma determinada preocupação com a eficiência escolar perpassa o conjunto das ações do Estado capitalista que se materializam na forma de políticas de avaliação e de controle social, usando, como regra geral para a educação e demais políticas sociais, a transposição de categorias advindas, muitas vezes, dos mais variados campos, como da economia ou do setor financeiro, por exemplo. Como é o caso da eficiência e da eficácia, que devem ser constantemente perseguidas no escopo das políticas públicas e, no caso específico da educação, esses elementos são perseguidos por constantes, e cada vez mais abundantes, exames externos que precisam ser considerados apenas em seus resultados.

\section{Eficiência e eficácia como mantras}

Ao nos reportarmos ao tratamento que vem sendo dispensado às políticas educacionais nos estertores dos anos de 1990, sobretudo em seu aspecto que se propõe avaliativo, em âmbito mundial ou nacional, percebemos que, subjacente à 
implementação dessas políticas, encontra-se um caudal de formulações, de slogans que as embasam e justificam como mantras. Estes encerram conceitos que advêm das mais variadas vertentes do pensamento que se intitula científico, partindo, por vezes, do campo econômico strictu sensu, em outras vezes até mesmo da biologia, como, por exemplo: eficiência, eficácia, clientela, produto, produtividade, ranking, cultivo, empowerment, empreendedorismo e outros. Tais slogans, mesmo carecendo de uma clarificação e discussão mais aprofundada, são amplamente exportados de forma "consagrada" e compõem não só os discursos e as políticas de organismos multilaterais, como também gozam de uma adesão crescente na implementação de políticas públicas, pois "expressam não apenas diretrizes para a educação, mas articulam interesses, projetam políticas, produzem intervenções sociais" (EVANGELISTA, 2009, p. 2).

Ínsita às políticas de avaliação dos anos noventa em diante, a educação eficiente desponta insistentemente como a grande conquista que deve ser realizada pela escola e pela universidade de forma geral, sobretudo em seu aspecto quantitativo. Porém, uma análise mais minuciosa revela que o que é tomado como educação eficiente resume-se naquela avaliada meritocraticamente e cujos resultados são amplamente expostos publicamente, resultando, portanto, num jogo de soma zero, tendo em vista que o processo retorna sempre em si mesmo, reforçando cada vez mais o processo avaliativo em detrimento do que se avalia.

Como não poderia deixar de ser, muitos aspectos que interferem e determinam o aprendizado, ou o não aprendizado por parte dos estudantes, são desconsiderados, recebendo atenção maior o rendimento dos alunos em testes ou em provas que intentam mensurar seus conhecimentos.

Essas avaliações são consideradas por nós como ações políticas, mais especificamente políticas públicas, que emanam do estado e caracterizam-se pelo papel deste no processo de conservação societal, que, muitas vezes, opera por inversão, apontando como causas o que seriam as consequências.

\section{Avaliação como política de estado}

Então, antes de mais nada, para conceituar essas políticas como ações que intentam materializar uma determinada forma de controle do estado, consideramos ser necessário retomar aqui o entendimento acerca da natureza do estado capitalista, locus do qual emanam, não de forma imediata, as ações que se materializam na implementação de políticas públicas de características que são afirmadas como sociais, como é o caso das políticas educacionais de cunho avaliativo. Essa conceituação se faz importante, pelo fato de que ela condensa o próprio entendimento de "equilíbrio instável" que toda política nascida sob o signo desse estado carregará. Nossa concepção de estado ancora-se em Engels, quando afirma que:

O Estado não é, pois, de modo algum, um poder que se impôs à sociedade de fora para dentro; tão pouco é 'a realidade da ideia 
moral', ou 'a imagem e a realidade da razão', como afirma Hegel. É antes um produto da sociedade, quando esta chega a um determinado grau de desenvolvimento; é a confissão de que essa sociedade se enredou numa irremediável contradição consigo mesma e está dividida por antagonismos irreconciliáveis que não consegue conjurar. Mas para que esses antagonismos, essas classes com interesses econômicos colidentes não se devorem e não consumam a sociedade numa luta estéril, torna-se necessário um poder colocado aparentemente por cima da sociedade, chamado a amortecer o choque e mantê-lo dentro dos limites da 'ordem'. Este poder, nascido da sociedade, mas posto acima dela e distanciandose cada vez mais, é o Estado (1984, p. 227).

É preciso considerar que o estado não se constitui como um ente em si, mas constitui-se pelo seu caráter processual e contraditório no que diz respeito às disputas que se colocam na base material da sociedade.

Essa organização, fruto dessas disputas, na impossibilidade de saná-las, as absorve no plano formal, no campo das políticas, ao mesmo tempo em que atua pela conservação das mesmas disputas que configuram a desigualdade, marca indissociável da sociedade regida pelo capital na base material da mesma sociedade que se pretende regular formalmente via políticas.

Portanto, dizendo isso, estamos categorizando o estado como espaço hegemônico de manutenção do status quo burguês, restando o espaço de luta contra hegemônica para uma explicação diversa da oficial, para a contestação e exigência de um tratamento diferenciado para as questões sociais e, consequentemente, para as políticas educacionais que o estado implementa.

As ações do Estado, em grande medida responsáveis pela manutenção das relações capitalistas de produção, assumem, na maioria das vezes, a feição de políticas, costumeiramente políticas públicas de característica social, que não são puras, mas que, uma vez implementadas, sofrem o choque da contradição de classe , de interesses divergentes. E, conforme Xavier e Deitos,

Uma das características do capitalismo e do Estado capitalista é a de que a política social nada mais é do que uma parte da síntese possível das tensões e disputas econômicas, sociais e políticas, e, portanto, das contradições que geram. Não é possível compreender a política social fora dessa dimensão; até porque a política social e, consequentemente, a política educacional isolada da dimensão do estado capitalista só seria possível como alternativa socialmente concebida para satisfazer, como universalização, as necessidades sociais coletivamente produzidas $(2006$, p. 69)

Sendo assim, as ações do estado caracterizam-se por um duplo papel, ao mesmo tempo em que são instrumentos de controle do social, operam um 
determinado tipo de tratamento aos reclames que se materializam pela desigualdade inexorável da sociedade. Segundo Freitas:

Na luta pelo controle do processo pedagógico das escolas, o Estado é cada vez mais disputado por forças sociais liberal-conservadoras que procuram assumir, por meio de avaliações externas, o controle e o fortalecimento dos processos de avaliação internos da escola (formais e informais) e a partir destes subordinar as categorias do processo pedagógico a seus interesses, vale dizer, preservar e aumentar o controle sobre os objetivos, o conteúdo e até sobre os métodos da escola (2014, p. 1092).

Nessa correlação de forças desiguais, as políticas educacionais, ainda que sejam estratégicas para o estado, podem expressar espaços táticos para a grande parcela da sociedade que sofre com a repartição desigual das riquezas, que, não obstante o fato de terem sido produzidas coletivamente, são apropriadas por um número cada vez mais reduzido de pessoas. Assim é com relação ao conhecimento, produção coletiva e histórica de toda a humanidade que nas escolas deveria ser socializado, é apropriado de forma privada por uma parcela cada vez menor de pessoas, sendo sonegado a uma parte cada vez mais significativa da sociedade.

As avaliações externas, tomadas exclusivamente em seus resultados, não esclarecem essa problemática, muito pelo contrário, atuam no sentido de obscurecer os verdadeiros motivos da não aprendizagem, ou da não obtenção de escores significativos por parte dos alunos, sobretudo oriundos da classe trabalhadora.

Dito isso, junto dessa compreensão da natureza do estado, como "escritório" onde se decidem as condições de manutenção dessa sociedade desigual, favorecendo poucos em detrimento de muitos, é preciso recuperar a validade da luta relacionada às ações políticas do próprio estado como forma de tensioná-lo no sentido da exacerbação de seu caráter classista.

Mantida essa estrutura estatal, vez por outra são implementados processos de reformulação do papel que o estado desempenha para a manutenção da sociedade e, para a temática de nossas discussões, faz-se necessário lembrar o processo de reaparelhamento do estado vivenciado no caso brasileiro, a partir dos anos $1990^{2}$, e em curso até os dias de hoje.

A reforma administrativa, mas também política e ideológica do Estado, é proposta a partir da implementação da chamada administração pública gerencial. Essa perspectiva de administração é apresentada como a solução para a crise do Estado, no que diz respeito ao seu modo de intervenção, e substitui ria o modelo racional legal ou burocrático que vinha orientando a administração pública (ZANARDINI, 2008, p. 69).

\footnotetext{
${ }^{2}$ Estamos nos referindo à Reforma do Estado iniciada ainda no governo de Fernando Henrique Cardoso, que teve como um dos principais mentores o então ministro Luiz Carlos Bresser Pereira.
} 
Neste caso especificamente, o estado vai colocando-se de forma cada vez mais restritiva no que diz respeito ao seu aporte financiador, ao mesmo tempo em que se agiganta em seu papel regulatório cerceador e controlador, portando seu aspecto avaliador, é o grande paradoxo do estado, que é mínimo no fomento, mas que se maximiza no controle, que, segundo Afonso,

[...] quer significar, em sentido amplo, que o Estado adoptou um ethos competitivo, decalcado no que tem vindo a ser designado por neodarwinismo social, passando a admitir a lógica do mercado com a importação para o domínio público de modelos de gestão privada cuja ênfase é posta nos resultados ou produtos dos sistemas educativos. Como assinala G. Walford (1990), esta ideologia da privatização, ao enaltecer o capitalismo de livre-mercado, conduziu a alterações e mudanças fundamentais no papel do Estado, tanto ao nível local, como ao nível nacional. Neste sentido, por exemplo, diminuir as despesas públicas exigiu não só a adopção de uma cultura gestionária (ou gerencialista) no sector público, como também induziu a criação de mecanismos de controlo e responsabilização mais sofisticados. A avaliação aparece assim como um pré-requisito para que seja possível a implementação desses mecanismos (1999, p. 74).

Esse processo demarca uma conjuntura que empurra os sujeitos, guardadas as suas especificidades, na busca de soluções atomizadas no sentido de responder ao afastamento do estado, sobretudo em seu aspecto de fomento, exemplos disso são as escolas "adotadas" pela comunidade e o pagamento de prêmios por produtividade nos exames externos realizados por algumas prefeituras.

Podemos destacar, dentre as várias políticas específicas para a educação que ocasiona uma mudança paulatina e cada vez mais voraz na ação dos docentes e demais sujeitos da educação o Índice de Desenvolvimento da Educação Básica - o IDEB $^{3}$. Tal política incide sobre toda a educação básica e foi respaldada no amplo movimento consubstanciado em torno do Plano de Desenvolvimento da Educação de $2007^{4}$. De forma correlata a implementação do referido plano ocorreu a instauração de um processo de controle externo das unidades escolares, como o Sistema Nacional de Avaliação da Educação Básica $\left(S A E B^{5}\right)$ que por sua vez, é capitaneado pela política da "maquiagem", estatística expressa no IBEB.

A criação do IDEB, calculado por escola, por rede e para o país inteiro, permitiu que fossem fixadas metas de desenvolvimento educacional de médio prazo para cada

\footnotetext{
${ }^{3}$ Criado em 2007, é formado pela junção de dois conceitos: o fluxo escolar e as médias de desempenho nas avaliações. É calculado a partir dos dados sobre aprovação escolar, retirados do Censo Escolar, e das médias de desempenho nas avaliações do Inep, o Sistema de Avaliação da Educação Básica (Saeb) - para as unidades da federação e para o país, e a Prova Brasil - para os municípios.

${ }^{4}$ Consideramos importante tomar essa política como marco, pois ela foi posta em prática quando ainda restavam três anos de vigência do Plano Nacional de Educação Lei no 10.172 de 2001, plano este que teve mais de $66 \%$ de suas metas não cumpridas por falta de financiamento por parte do Estado.

${ }^{5}$ Atualmente, o Sistema de Avaliação da Educação Básica (Saeb) é composto por um conjunto de avaliações externas em larga escala.
} 
uma das instâncias de aplicação do índice e também metas intermediárias de curto prazo que possibilitam o controle mais rígido da "reforma qualitativa dos sistemas educacionais" (BRASIL, 2007b).

Em 2005, foi "tirada uma radiografia", em que o IDEB, para o país referente aos anos iniciais do Ensino Fundamental, foi de 3,8 pontos, contra uma média estimada dos países desenvolvidos de seis pontos, número que expressa a meta nacional a ser perseguida até 2021. Logo, o norte avaliativo colocado nos índices dos países desenvolvidos, que deverá ser alcançado pelo Brasil, está marcado previamente numa grande festa no ano em que o Brasil completará 200 anos de sua independência.

Dessa forma, ao estabelecer esse norte, o estado brasileiro condicionou a forma e o conteúdo dos trabalhos das escolas para que esse escore fosse certamente alcançado, logo, as escolas passaram a adotar os testes externos como balizadores dos currículos e a ascensão dos índices foi formatando o aprendizado, ou o não aprendizado, por parte dos alunos em sala de aula.

As escolas seguem "prisioneiras", em grande medida, dos ditames dos testes avaliativos em larga escala, uma vez que o estado adota o expediente de vincular o investimento da educação ao atingimento dos escores supostamente mensurados e indicados pelo IDEB de cada uma das unidades escolares da federação.

Então, internamente, o espaço para a contradição com a política de avaliação ganha contornos cada vez mais estreitos, pois, além do índice ser utilizado para auxiliar no contingenciamento do financiamento da educação, os conteúdos e a forma como esses são dispostos nos testes de avaliação em larga escala direcionam e determinam os conteúdos trabalhados pelas escolas, na ânsia de, assim, obterem melhor rendimento e garantia de financiamento.

Essa política acaba colocando a alguns governantes, aos docentes e aos demais sujeitos da escola formas individuais, quando muito particulares, de recorrência no que diz respeito ao financiamento e à manutenção das condições escolares. Como exemplo disso, podemos citar os décimo-quartos salários oferecidos a docentes e os prêmios pecuniários oferecidos às escolas que atingem ou melhoram seu IDEB ${ }^{6}$.

Podemos afirmar que a coleta e a divulgação dos resultados obtidos pelos alunos nos testes em larga escala teriam determinada relevância se fossem considerados de acordo com a natureza que possuem, a saber, refletores de elementos singulares, e que não são desconsideráveis em si, porém, o que assistimos é a adoção, pelo estado, dos resultados emanados dessas políticas como se fossem universais e diagnósticos do quadro geral da qualidade da educação.

\footnotetext{
${ }^{6}$ Conforme decreto municipal no 23,212 de 15 de julho de 2014 de Foz do Iguaçu no Paraná que regulamenta "O presente instrumento tem por finalidade pactuar as metas a serem realizadas pela Secretaria Municipal da Educação e a conceder o Prêmio por Desempenho, com base nos resultados do índice de Desenvolvimento da Educação Básica - IDEB - a serem divulgados no ano de 2014, decorrentes do alcance, no ano letivo de 2013, das metas fixadas neste Decreto." (FOZ DO IGUAÇU, 2014). A esse respeito, consultar: https://leismunicipais.com.br/a/pr/f/foz-doiguacu/decreto/2014/2321/23212/decreto-n-23212-2014-regulamenta-e-disciplina-o-acordo-metas-doprogramagestao-para-resultados-conforme-especifica.
} 
Logo, a avaliação externa da educação via ação política do estado, não é uma mera componente das políticas educacionais dele emanadas, ela constitui um dos mais importantes mecanismos que cumprem a dupla função de controlar a sociedade, ao mesmo tempo em que se materializa na ausência do estado no que diz respeito ao financiamento dessas mesmas políticas. Tendo em vista que os resultados obtidos no processo de ranqueamento das escolas públicas, na maioria das vezes, condicionam e determinam a forma de atenção que o estado dispensa para o atendimento na sua função de mantenedor.

As escolas públicas centram suas ações no alcance de escores, uma vez que a política atrela o IDEB ao processo de financiamento e gestão educacional, disputando, muitas vezes, por prêmios temporários que não garantem e não possibilitam segurança no sentido da manutenção desses ganhos relativos.

Essa mistura de - accountability com avaliação, a meu ver, vai ser danosa para a área de avaliação, porque, inclusive, não entrará na área da educação. Continuará fora da área da educação se for colocada dessa maneira. $\mathrm{Na}$ área da educação não existe ganhador $\mathrm{e}$ perdedor. A área da educação é área de direito, e área de direito não tem ganhador e perdedor. A área do mercado, sim. Eu jogo na bolsa, sei que posso ganhar e posso perder. E se perder, não tenho direito de reclamar, assinei até um contrato. Se eu investir 100 e cair para 70, o problema é meu. Faz parte do jogo. O mercado lida dessa forma. Na área da educação, não pode haver perdedor. O problema começa aí: a lógica de funcionamento não se adapta à lógica da área educacional porque não podemos conviver com perdedores (FREITAS, 2013, p. 360).

Num processo de culpabilização dos sujeitos, escolas e alunos são colocados uns contra os outros, o que dificulta uma reflexão conjunta a respeito do buraco sem fundo para o qual caminha a educação pública. Uma vez mantida essa estruturação e com o paulatino alinhamento dos currículos das escolas a esse movimento, podemos afirmar, sustentados em Freitas (2014), que os cérebros dos sujeitos da escola pública seguem aprisionados por esse movimento que se pretende avaliativo da educação nacional, pois, do lado das escolas, essas tendem cada vez mais a adotar estratégias em torno do alcance de escores, condição que garante a sua existência, dado o afastamento do estado dessa função.

Isso se dá em detrimento da realização de outra função social da escola que não seria o alcance de escores, mas, sim, a ligada a outro projeto de sociedade, a saber, a socialização consistente do conhecimento elaborado histórica e coletivamente pela humanidade.

Outro traço marcante desse aprisionamento de cérebros, no quadro das políticas implementadas a partir dos anos 1990, revela-se pelo efeito provocado na ação do estado pelo movimento de reestruturação produtiva que recrudesce, de forma coetânea e determinante com relação ao movimento de reformulação do seu papel. Para a Educação Básica, esse quadro assinala a sina de preparar os sujeitos 
para a disposição no mercado de trabalho, onde, devido inclusive aos novos incrementos produtivos, não há lugar para todos.

À avaliação escolar meritocrática cabe um papel preponderante sobretudo como instrumento de conformação, pois, aos desempregados ou aos alojados na economia informal, que, segundo o Banco Mundial (2004), têm mais chance de "tombar na pobreza", mais do que não possuir, convêm que acreditem não possuir qualificação e que seu quadro de desemprego e consequentemente de pobreza, daí advém.

Porém, uma análise da base material da sociedade brasileira, para a qual esse modelo de educação deveria responder, nos leva impreterivelmente a considerar a forma como o Brasil se insere no complexo movimento de materialização da divisão mundial do trabalho, implementada pelos países do núcleo duro do capital e que deve ser seguida obedientemente pelos chamados países periféricos, como é o caso do Brasil?.

Essa política indica que o setor terciário da produção, a produção de matériaprima e o setor de comodities continuarão sendo o carro-chefe da produção de riqueza nacional ${ }^{8}$. Sendo assim, indagamo-nos a respeito da natureza que deve materializar-se na educação, se é pensada como forma de responder a essa necessidade produtiva?

A política avaliativa desloca-se cada vez mais da possibilidade de socialização do conhecimento o que nós consideramos como qualidade em educação, muito embora não hesite em propor uma determinada modalidade de qualidade como seu principal objeto. A primeira noção de qualidade estaria ligada a uma concepção de educação como processo, enquanto que a segunda, a que é perseguida pelas avaliações em larga escala, privilegia exclusivamente o foco nos resultados.

Esta definição coaduna-se com o movimento de proposição das chamadas "escolas eficazes", que propala dentre outras medidas a autorresponsabilização dos professores pelo desempenho dos alunos, por meio da incorporação de uma nova racionalidade para orientar suas práticas, concretizando a gestão por resultados (SANTOS, 2012).

\section{Base nacional comum curricular}

Ao nos remetermos para a atualidade, temos o recrudescimento e aprimoramento desse sistema que se pretende avaliativo da escola, materializado na Base Nacional Comum Curricular - BNCC (BRASIL, 2018), que segundo Macedo:

No que tange a bases nacionais comuns, as articulações políticas culminaram com a reiteração de sua necessidade no Plano Nacional

\footnotetext{
${ }^{7}$ Segundo dados do IBGE (BRASIL, 2018), O setor de serviços é o setor com maior participação na economia. No 1o trimestre de 2018 , o setor de serviços representou $72,5 \%$ do valor adicionado do PIB brasileiro. A indústria alcançou os $20,8 \%$ e a agropecuária, $6,7 \%$.

${ }^{8}$ A Financeirização é a lógica de produção de lucro do capitalismo atualmente, nesse ponto o capital financeiro precisa se descolar do setor produtivo, que não é o mesmo para todos os países, para compor o campo especulativo que não produz riqueza nova.
} 
de Educação (PNE) finalizado em 2014. O documento distingue base nacional curricular comum (BNCC) de DCN e define que "União, Estados, Distrito Federal e Municípios [devem pactuar] (...) a implantação dos direitos e objetivos de aprendizagem e desenvolvimento que configurarão a base nacional comum curricular do ensino fundamental" (MEC, 2014, meta 2). No PNE (MEC, 2014), a BNCC é relacionada às metas que dizem respeito à universalização do ensino fundamental (metas 2 e 3); à avaliação e ao IDEB (meta 7); e à formação de professores (meta 15) (2014, p. 1535).

Antes mesmo de vir ao lume, o movimento social que se construiu em torno da elaboração dessa política curricular, contou com a forte participação daqueles que Freitas (2014) nomeia como sendo os reformadores empresariais da educação, composto por "políticos, mídia, empresários, empresas educacionais, institutos e fundações privadas e pesquisadores alinhados com a ideia de que o mercado e o modo de organizar a vida privada é uma proposta mais adequada para consertar a educação". Constam de suas estratégias elementos como: fortalecimento da gestão, avaliações externas em larga escala ou censitárias, responsabilização/meritocracia, criação de um mercado educacional e privatização.

Este conjunto de dispositivos representa o maior avanço dos reformadores empresariais da educação no cenário educacional brasileiro e, entre outros aspectos, visa abrir o campo educacional para "empresas educacionais confiáveis" do mercado de consultoria, materiais didáticos, avaliação, venda de tecnologia, organização de big data entre outras, que operam na difusão de métodos tecnicistas e introduzem nas redes e escolas processos de gestão verticalizados que permitem elevar o grau de controle sobre os profissionais da educação, a título de garantir a obtenção de metas e índices nas avaliações externas, definindo os objetivos, a avaliação, a forma e o conteúdo da escola (FREITAS, 2014, p. 1085).

Porém, o que gostaríamos de ressaltar é que a BNCC materializa uma pseudopolítica curricular, tratando-se em termos políticos, de mais do mesmo, ou seja, o fortalecimento do controle por parte do estado da política educacional via o fortalecimento do movimento avaliativo escolar em larga escala, porém, agora, com uma sutileza mordaz:

A BNCC proposta reforça as tendências internacionais de centralização curricular, verificadas nos países centrais do capitalismo, com o objetivo de viabilizar a avaliação em larga escala, externa às unidades escolares, e, em consequência, promover a responsabilização dos docentes e dos gestores das respectivas escolas pelos resultados da aprendizagem, desconsiderando as condições efetivas da realização das atividades educacionais, como a 
infraestrutura disponível nestas escolas e as condições do trabalho docente (ANDES, 2016, p. 10).

Ademais, todo o documento é perpassado pela valorização da necessidade de estabelecimento de uma ordem subjetiva, travestida em competências ${ }^{9}$, a ser alcançada por parte dos alunos das escolas e de que tal subjetividade deve ser objeto do trabalho das escolas. Segundo Bruening:

Solidariedade, amizade, responsabilidade, colaboração, empatia, organização, ética, cidadania, honestidade. Esses valores (ou características) - tão desejáveis nos relacionamentos humanos e cada vez mais requisitados e necessários nos dias de hoje deverão ser ensinados, praticados ou, pelo menos, estimulados também nas escolas. É o que dizem as novas diretrizes da Base Nacional Comum Curricular (BNCC). A partir de 2020, todas as escolas brasileiras terão de incluir as habilidades socioemocionais nos seus currículos. Ou seja, haverá a necessidade de adaptar os programas escolares e treinar os professores para que possam ministrar essas novas competências - que têm foco em habilidades não cognitivas, muito mais relacionadas ao comportamento e à administração das próprias emoções, mas que impactam positivamente o indivíduo e a relação dele com o mundo ao seu redor (2018, s/p.).

Essa nova subjetividade ${ }^{10}$ a ser perseguida consubstancia-se naquilo que está sendo anunciado como objetivos não cognitivos ou socioemocionais que demarcariam o trabalho das escolas e que seriam indicados pelo Estado.

Esses aspectos de personalidade também são chamados de conhecimento ou habilidades não cognitivas, ou de traços de caráter, ou pelo termo soft skills, importado do inglês (habilidades suaves, em contraponto às hard skills, habilidades duras, como matemática, ciências e leitura). Essas habilidades suaves são tradicionalmente relegadas a segundo plano, encaradas como traço imutável da personalidade ou responsabilidade da educação familiar. Mas estudiosos do mundo do trabalho têm afirmado já há algum tempo que elas são as competências mais apreciadas nos

\footnotetext{
${ }^{9}$ Na BNCC, competência é definida como "a mobilização de conhecimentos (conceitos e procedimentos), habilidades (práticas, cognitivas e socioemocionais), atitudes e valores para resolver demandas complexas da vida cotidiana, do pleno exercício da cidadania e do mundo do trabalho" (BRASIL, 2018, p. 8).

${ }^{10}$ A novidade talvez se restringisse ao Brasil, uma vez que políticas dessa natureza eram adotadas nos EUA, como asseverou Bruering $(2018, \mathrm{~s} / \mathrm{p})$ : "Pesquisas em todo o mundo apontam que o melhor aprendizado ocorre em ambientes seguros e saudáveis, ou seja, o aprendizado ocorre em um contexto social. De certo modo, é difícil separar aspectos sociais e emocionais de processos de aprendizagem acadêmica. Além disso, os componentes das habilidades socioemocionais, no caso dos Estados Unidos, estão totalmente ligados a requisitos da American Common Core [a base norteadora de educação daquele país, o que similarmente está acontecendo com a BNCC, no Brasil], e autorregularão trabalho em equipe, empatia, cooperação e uma série de valores que fortalecem o caráter humano e tão necessários para as demandas do século 21."
} 
profissionais, a ponto de serem centrais para o que chamam de "habilidades para o século XXI". Num tempo em que o conteúdo "duro" está tão disseminado, o que faz diferença, dizem esses estudiosos, é a forma de aplicá-los. E isso exige habilidades "suaves": saber ouvir, equilíbrio emocional ante problemas, resolução de conflitos (OSHIMA, 2015, s/p).

Oshima (2015), em artigo intitulado "Eduque suas emoções", alardeia o fato de que: "As escolas públicas começam a ensinar os alunos a lidar com os sentimentos. Pesquisas mostram que esse é o caminho certo para promover mais igualdade de oportunidades". As pesquisas mencionadas contaram com o apoio do Instituto Ayrton Senna ${ }^{11}$, organismo oficioso no que se refere a implementação de políticas educacionais no Brasil, que, em parceria com alunos de Harvard, iniciaram pesquisas em torno do ensino dos chamados componentes socioemocionais na escola.

Segundo Oshima:

As secretarias de Educação de São Paulo e do Rio de Janeiro incorporaram a educação socioemocional ao currículo regular das escolas estaduais de ensino integral de suas redes. No Rio de Janeiro, uma parceria com o Instituto Ayrton Senna tornou viável o desenvolvimento do programa Solução Educacional para o Ensino Médio, que está funcionando em 56 escolas. Em São Paulo, uma aliança com a ONG Vila da Educação possibilitou a criação do programa Compasso, criado a partir do americano Second Step (segundo passo), metodologia que existe há 20 anos. O Compasso está em 17 escolas (negritos do original, 2015, s/p.).

São elencadas como competências socioemocionais, ou não cognitivas, a cooperatividade, consciência, liderança, planejamento, valores, comunicação, autoeficácia, motivação, ética, apresentação, ansiedade, sensibilidade, extroversão, coleguismo, resiliência, caráter, autodestreza, abertura, persistência, profissionalismo, autoestima, entusiasmo, criatividade e colaboração ${ }^{12}$. Essa extensa listagem de componentes que, na sua maioria, são afetivos, leva a reflexão de que cada um desses componentes, em maior ou em menor medida, são trabalhados todos os dias pelas escolas do Brasil, seguindo, é claro, a concepção de mundo de cada professor que está à frente do processo de ensino e aprendizagem Porém, segundo Abed (2014), é preciso formar tais conceitos no trabalho dos professores, os ensinantes como os denomina, pois são os principais protagonistas na mudança do cenário educacional. Afirma a autora:

\footnotetext{
${ }^{11}$ Segundo informação do próprio instituto, as pesquisas começaram em 2011. Para mais informações consulte: http://www.institutoayrtonsenna.org.br/todas-as-noticias/pesquisadores-criam-ferramentapara-medircompetencias-socioemocionais-na-escola/

12 Todas essas competências estão listadas no site: http://educacaosec21.org.br/. Aceso em: 20 jun. 2016.
} 
É importante que o professor não só domine os conteúdos que ensina (dimensão cognitiva), mas também tenha consciência dos sentidos que ele, professor, atribui a esses conhecimentos, aos aspectos energéticos e afetivos com que reveste a sua relação com o saber e com os alunos (dimensão emocional, social e ética). Nesse sentido, o desenvolvimento das habilidades socioemocionais dos alunos, como motivação e engajamento, pode, e deve, ser promovido pelo entusiasmo e prazer com que 0 ensinante apresenta o conhecimento aos alunos (ABED, 2014, p. 59-60).

Afirmações como essas, colocadas em tom alvissareiro, desconsideram o papel que historicamente os professores desempenham nas escolas do Brasil à frente do que Freitas (2014) denominou como avaliações informais e intentam moldar esse papel segundo um padrão externo.

O papel das avaliações informais é decisivo no progresso das crianças. Pode-se mesmo dizer que ao ser reprovado pela avaliação formal (seja interna ou externa) o aluno foi reprovado, antes, na relação de ensino a qual é perpassada pela avaliação informal. Este processo cria, em sala de aula, um histórico de juízos de valores que são definidores das possibilidades de progresso dos alunos, pois afetam as estratégias metodológicas seguidas pelo professor e a forma de envolvimento dos estudantes. São estes processos que conformam culturalmente $o$ aluno ou promovem o seu afastamento. Pela avaliação informal o professor cria nas relações de ensino uma autoimagem da criança e produz uma autoimagem também na criança. A autoimagem é um poderoso instrumento de motivação ou desmotivação, na dependência de seu conteúdo, e tem relação com a própria identidade cultural do estudante (2014, p. 1096-1097).

É esse amplo movimento em torno da padronização da "construção correta" de cada um desses componentes socioemocionais ou não cognitivos, que nos preocupa, pois estamos caminhando para uma homogeneização emocional ${ }^{13}$, conduzida e verificada pelo Estado, onde se defende que:

Todo professor sabe da importância de lidar com aspectos emocionais dos alunos e de ajudá-los a fazer o mesmo. De forma geral, fazem isso no dia a dia, de forma intuitiva, na base da tentativa e erro. A eficácia depende da experiência e da paciência de cada professor. O rastreamento e a avaliação dos melhores métodos, como a OCDE se propõe a fazer, ajudarão a montar

\footnotetext{
${ }^{13}$ Como recentemente denunciado por ANPED (2014): "O estabelecimento de uma hierarquia valorativa, pretensamente universal e imparcial, expressa a desconsideração da desigualdade social econômica e a diversidade cultural da socie-dade brasileira, bem como as diferenças entre os sujeitos, o que possivelmente representa a naturalização de valores oriundos das classes mais favorecidas. O que se busca é a padronização desses valores?".
} 
treinamentos sistematizados para os professores, que são peçaschave nesses programas (OSHIMA, $2015 \mathrm{~s} / \mathrm{p}$ ).

\section{Considerações finais}

E para dar cabo e alinhar essa tarefa, como já ocorre para a tentativa de mensura dos componentes cognitivos, já existe uma ferramenta, batizada de SENNA, por meio da aplicação da qual se pretende mensurar, de forma externa e em larga escala, os componentes afetivos.

O SENNA (sigla em inglês para avaliação nacional de competências socioemocionais ou não cognitivas) inclui um questionário com até 92 perguntas respondidas pelo estudante sobre si mesmo (seu comportamento em determinadas situações) cujas respostas a cada questão representam um indicador sobre os cinco grandes domínios de personalidade (extroversão, conscienciosidade, abertura a novas experiências, amabilidade e estabilidade emocional) e sobre um sexto aspecto chamado Lócus de Controle (que reflete em que medida o indivíduo atribui situações vividas a atitudes tomadas por ele, ou ao acaso e decisões tomadas por terceiros) (ROCHA, 2014, $s / p)$.

Com a implementação de mais esse instrumento de avaliação em larga escala, o que se projeta para o futuro é um aprimoramento maior de todo o arsenal avaliativo de que já dispõe o Estado brasileiro, o que, a nosso ver, muito ao contrário das motivações alardeadas, aumentará mais ainda o controle do social e poderá representar a materialização de um movimento padronizador de emoções, construídas e pré-planejadas. A respeito do SENNA, Rocha afirma:

É um teste padronizado, que pode ser parte integrante de alguma prova em larga escala já feita para avaliar conhecimentos de matemática e português, como a Prova Brasil, por exemplo", afirmou Tatiana Filgueiras, Coordenadora de Avaliação do Instituto Ayrton Senna. "Agora, o instrumento está disponível para uso de políticas públicas, com orientações para a aplicação e análise dos dados. Esse é um caminho para integrar de forma intencional nos currículos das escolas as ações para estimular competências socioemocionais", disse $(2014, \mathrm{~s} / \mathrm{p}$.).

Essa forma de testagem também se alinha ao recrudescimento das políticas avaliativas de caráter externo implementadas na educação brasileira a partir dos anos 90/2000, e essas ações, na forma de políticas, emanam do Estado avaliador/verificador, que, ao mesmo tempo em que aumenta sua capacidade regulatória e de controle objetivo e agora, subjetivo, minimiza sua importância no que diz respeito ao fomento da educação. 
Urge, então, firmarmos posição que se coloque de forma crítica e contrária a todo esse amplo movimento que materializa uma verificação sumária de característica privatista e produtivista, pois, atrelado a esse movimento, pela batuta dos reformadores empresariais, o que se tem em mira é um amplo estabelecimento de parcerias, as chamadas parceria público-privadas, venda de apostilas, escolas públicas geridas pelo poder privado, além de cursos oferecidos por fundações ${ }^{14}$, o que impactará negativamente em todas as instituições de ensino.

Todo esse movimento de cariz empresarial se contrapõe de forma incisiva a uma perspectiva de educação que leve em consideração a apropriação do conhecimento por parte dos alunos, uma vez que, dado o encarceramento dos cérebros, agora pretende também encarcerar os corações dos estudantes oriundos principalmente da classe trabalhadora. Mais uma vez apoiados em Freitas, podemos afirmar que:

A sala de aula e a escola não são uma linha de produção sobre a qual pode-se cravar uma série de relógios que indicam se a produção está sendo feita segundo as metas ou se está havendo algum "desvio". Muito diferente disso, a escola e a sala de aula se assemelham a uma rede de relações multilaterais que não deve sofrer interferências não planejadas de fora, e na qual as ações devem ser acordadas, ou seja, negociadas entre os variados participantes do processo. Ações não planejadas de fora para dentro destroem a confiança relacional vital para o desenvolvimento de um trabalho que é antes colaborativo entre seus participantes. A ideia da concorrência que orienta os negócios dos empresários e que se expressa no "premiar, punir e corrigir os desvios da meta" não é boa para a educação, simplesmente porque esta não é uma atividade concorrencial (2014, p. 1099).

O que se coloca, então, na ordem do dia é a exigência de um modelo de avaliação que leve em conta o processo que se desenvolve nas escolas, o que exige uma maior atenção para os elementos endógenos que circundam todo o processo de ensino e aprendizagem, como o projeto de sociedade, projeto de educação, elementos infraestruturais e institucionais, bem como melhores condições de trabalho e de estudo, condições que se colocam contrárias ao aprisionamento de mentes e corações intentado pelo Estado brasileiro em suas políticas de cunho meritocrático, como são exemplos o amplo sistema de avaliação em larga escala de componentes cognitivos, ou não cognitivos, e socioemocionais que está colocado na ordem do dia para as escolas e para seus principais sujeitos.

\footnotetext{
${ }^{14}$ Vários cursos já são oferecidos, alguns em parcerias com instituições privadas, como se pode constatar em: https://assine.novaescola.org.br/cursos?gclid=Cj0KCQjw08XeBRCOARIsAP_gaQBtP2Ww69SyYRDwEqt2qJ OaG8rxtplaDcDogoW4CxG78SDak3LepS4aAoL4EALw_wcB
} 


\section{Referências}

ABED, Anita Lilian Zuppo. 0 desenvolvimento das habilidades socioemocionais como caminho para a aprendizagem e o sucesso escolar de alunos da educação básica. São Paulo: 2014.

ANDES. Sindicato Nacional. Projeto do Capital para a educação: Análises e ações para a luta. Cartilha produzida pelo Grupo de Trabalho de Política Educacional (GTPE). 2016. Disponível em: http://portal.andes.org.br/andes/print-ultimas-noticias.andes? id=8031. Acesso em julho de 2018.

ANPED. Carta Aberta sobre avaliação em larga escala de habilidades não cognitivas de crianças e jovens. 8 de Novembro de 2014. Disponível em: http://www.anped.org.br/news/carta-aberta-sobre-avaliacao-em-larga-escalaehabilidades-nao-cognitivas-de-criancas-e-jovens. Acessado em 21 jul. 2019.

AFONSO, A. J. Políticas Educativas e Avaliação Educacional: Para uma análise Sociológica da Reforma Educativa em Portugal (1985-1995) Edição do Centro de Estudos em Educação e Psicologia, Instituto de Educação e Psicologia, Braga, 1999.

BRASIL. Lei n. 13005 de 25 de junho de 2014. Aprova o Plano Nacional de Educação PNE e dá outras providências. Disponível em: http://www2.camara.leg.br/legin/fed/lei/2014/lei-13005-25-junho-2014778970publicacaooriginal-144468-pl.html. Acessado em 02 dez. 2017.

BRASIL. Base Nacional Comum Curricular. Brasília, 2018. Disponível em: http://basenacionalcomum.mec.gov.br/wp-content/uploads/2018/02/bncc20dezsite.pdf. Acessado em 20 set. 2018.

BRASIL. Contas nacionais trimestrais. Tabela 1846. Disponível em: https://sidra.ibge.gov.br/tabela/1846\#/n1/all/v/all/p/201802/c11255/90687,90691,9 0696,90705,90706,90707,93404,93405,93406,93407,93408,102880/I /v,,c11255+t+p/resultado. Acessado em 12 dez. 2019.

BRUENING, Pamela. A história, os pilares e os objetivos da educação socioemocional. Revista Educação. Edição 251, 2018. Disponível em: http://www.revistaeducacao.com.br/historia-os-pilares-e-os-objetivos-daeducacaosocioemocional/. Acessado em 20 set. 2018.

ENGELS, F. A origem da família, da propriedade privada e do Estado. São Paulo : Global, 1984.

FOZ DO IGUAÇU. Decreto n. 23212-2014. Regulamenta e disciplina o acordo metas do programa gestão para resultados conforme especifica. Disponível em: https://leismunicipais.com.br/a/pr/f/foz-doguacu/decreto/2014/2321/23212/ decreto-n-23212-2014. Acessado em 02 abr. 2016.

FREITAS, Luiz Carlos de. Políticas de responsabilização: entre a falta de evidencia e a ética. Cadernos de Pesquisa, São Paulo, vol 43, no 148, pgs. 348-365., jan/abr, 2013. 
FREITAS, Luiz Carlos de. Os Reformadores empresariais da educação e a disputa pelo controle do processo pedagógico na escola. Educ. Soc., Campinas, v. 35, №. 129, p. 1085-1114, out.-dez., 2014.

MACEDO, Elisabeth. Base nacional curricular comum: novas formas de sociabilidade produzindo sentidos para educação. Revista e-Curriculum, São Paulo, v. 12, n. 03 p.1530 - 1555 out./dez. 2014 ISSN: 1809-3876. Programa de Pós-graduação Educação: Currículo - PUC/SP. 2014.

NERI. Marcelo. Número de pobres cresce "dois Uruguais" no Brasil entre 2014 e 2017, aponta FGV. Disponível em: https://www.cps.fgv.br/cps/bd/clippings/uc313.pdf. Acessado em 17 set. 2018. OSHIMA, FLÁVIA YURI. Eduque suas emoções: As escolas públicas começam a ensinar os alunos a lidar com os sentimentos. Pesquisas mostram que esse é o caminho certo para promover mais igualdade de oportunidades. Disponível em: http://epoca.globo.com/ideias/noticia/2015/09/eduque-suas-emocoes.html. Acesso em: 15 jun. 2016.

ROCHA, Marília. Pesquisadores criam ferramentas para medir competências socioemocionais na escola. 2014. Disponível em:

http://www.institutoayrtonsenna.org.br/todas-as-noticias/pesquisadorescriamferramenta-para-medir-competencias-socioemocionais-na-escola/. Acesso em: junho de 2016.

SILVA JUNIOR. Luiz Onorato da e SAMPAIO. Yony. Notas Sobre Pobreza e Educação no Brasil. Revista Problemas del Desarrollo, v. 163, n. 41, pgs. 75/ 97 octubre-diciembre 2010. Disponível em: http://www.scielo.org.mx/pdf/prode/v41n163/v41n163a5.pdf. Acesso em: 15 out. 2018.

XAVIER, Maria Elizabete Sampaio Prado e DEITOS, Roberto Antonio. Estado e Política Educacional no Brasil. In: DEITOS, Roberto Antonio e RODRIGUES, Rosa Maria (orgs.) Estado, Desenvolvimento, Democracia \& Políticas Sociais. Cascavel: EDUNIOESTE, 2006.

ZANARDINI, Isaura Monica Souza. A Reforma do Estado Brasileiro no contexto da Globalização e da pós-modernidade. In: ZANARDINI, Isaura Monica Souza e ORSO, Paulino José (orgs.). Estado, Educação e Sociedade Capitalista. Cascavel:

EDUNIOESTE, 2008. 